\title{
Seismic Risk Analysis Using OpenQuake and Its Application in Iran
}

\author{
Changlong $\mathrm{Li}^{\dagger}$ \\ Institute of Geophysics, China Earthquake Administration, Beijing 100081, China
}

\begin{abstract}
Strong earthquake ground motion can cause destruction of the buildings, and lead to earthquake disasters. Therefore, seismic risk analysis has important practical and social value. Global Earthquake Model (GEM) Foundation is committed to addressing the global seismic risk analysis issues, and to providing scientific support for global social development. This paper explained the main target and functions of GEM and the ways to its tool (OpenQuake software) to make seismic risk analysis. We also introduced the algorithms of seismic risk analysis. At last, we took an example of Iran to calculate the seismic risk distribution based on the seismic hazard all over the country. We can conclude that the southeastern part of Iran has higher seismic risk where may suffer serious loss from earthquake disasters in the next 50 years.
\end{abstract}

Key words

Seismic risk; Global Earthquake Model (GEM) Foundation; OpenQuake; Iran

\section{基于 OpenQuake 的地震风险分析}

\section{及在伊朗的应用}

\author{
李昌珑 \\ 中国地震局地球物理研究所, 北京 100081 , 中国
}

摘要：大地震产生的强地震动会对建筑物造成破坏, 产生地震灾害。因此, 地震风险分析的 社会意义重大。全球地震模型（GEM）基金会致力于全球的地震风险分析工作，为全球的 社会发展提供科技支持。本文介绍了 GEM 的主要职能及其地震风险分析软件 OpenQuake 与 算法。最后以伊朗为例计算了该国地震风险分布情况。得出的结论是伊朗东南部未来 50 年 面临较高的地震风险。

关键词: 地震风险; 全球地震模型基金会; OpenQuake; 伊朗

Sponsored by: National Natural Science Foundation of China (41704045). 


\section{Introduction of GEM}

Strong earthquake ground motion can cause destruction of the buildings, and lead to earthquake disasters. It is of great help to prevent earthquake disasters by providing appropriate seismic fortification parameters for structural design. Therefore, seismic hazard and risk assessment has important practical and social value.

Founded in 2009, Global Earthquake Model (GEM) Foundation is a global association of seismic hazard analysis and seismic risk analysis, headquartered in Pavia, Italy. Kate Stillwell is currently the head of the GEM Science Department. Since its foundation, GEM has worked with global scientists on global seismic risk analysis (Danciu et al., 2010; Crowley et al., 2010).

\section{OpenQuake virtual machine and its seismic risk algorithm}

In order to meet the high accuracy, high reliability and high adaptability of earthquake risk assessment, GEM has developed OpenQuake as its main product and tool. It is an open-source software for seismic hazard and risk assessment. A complete set of OpenQuake installation files, user manuals and source codes can be downloaded from GEM's official website at http://www.globalquakemodel.org/. It runs on Python and Java language (Silva et al., 2012) and operates on Linux virtual machines. A variety of seismic hazard and risk assessment models, (Stewart et al., 2012a; Pagani et al., 2015), sophisticated algorithms and processes (Silva et al., 2012) and user-friendly user interfaces (Weatherill, 2012) enable it to perform many seismic risk analysis functions.

OpenQuake's seismic risk analysis model includes seismic hazard, vulnerability, exposure, and groundmotion field model. The seismic hazard model is derived from the PSHA model. The vulnerability model describes the loss rate distribution under a given intensity. The exposure model includes type, location and taxonomy of assets. The ground motion field model represents a random variation of GMPE (including for the same earthquake and between different earthquakes).

OpenQuake's seismic risk analysis algorithm is divided into four types (Silva et al., 2012):

(1) scenario risk algorithm

Scenario risk algorithm calculates the deterministic loss of a single earthquake. The algorithm inputs an earthquake rupture and a GMPE to calculate the ground motion field. Other inputs include vulnerability model and exposure model. The outputs are loss maps and loss statistics.

(2)Event-based probabilistic risk algorithm

This algorithm is based on the probability of loss and loss occurring from probabilistic seismic hazard calculations. The loss is calculated by setting a single seismic event, and the time of occurrence of the earthquake is random. The loss curves and loss maps can be calculated for different return periods, and the damage distribution of each asset and total assets can be output.

(3) PSHA based risk algorithm

This algorithm uses the risk curve of probabilistic seismic hazard to calculate the loss transcendence curve of each asset. The probability of a single asset losing more than a certain percentage at a certain location is obtained, and the probability loss map is output. Unlike other algorithms, this algorithm cannot output the total loss curve because the residuals and the vulnerability of the ground motion field are not taken into account.

(4) Ratio of profit/cost algorithm 
This algorithm is used to calculate whether the improvement measures of an existing building bring benefits from an economic point of view. It provides the expected loss estimate before and after the measures, and can calculate the ratio between the economic benefits and the cost after the measures to determine the transformation plan of the building.

All four kinds of algorithms are made up of several calculation modules. The calculation area, algorithm type, input path, and output type also need to be defined in the calculation. The four algorithms require input of the vulnerability and the exposure model, and the calculation flow charts have a similar form, as shown in Figure 1.

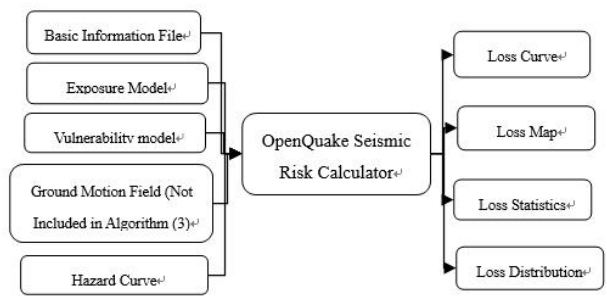

Fig. 1 Flow chart of seismic risk analysis by Openquake

\section{Seismic risk analysis of Iran}

Situated in the Middle East, Iran is separated into 30 provinces (Figure 2a). Iran's seismic hazard map (PGA with 10\% probability of exceedance in 50 years) is shown in Figure 2b (Danciu et al, 2015). To calculate the seismic risk, we take the taxonomy of reinforced concrete buildings as an example. The vulnerability curve of such kind of building is shown in Figure $2 \mathrm{c}$, and its exposure model in Iran is shown in Figure 2d.

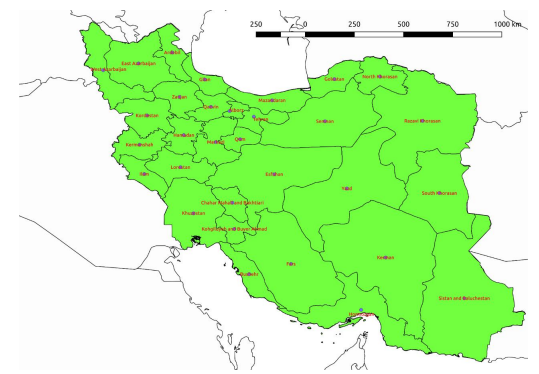

(a)

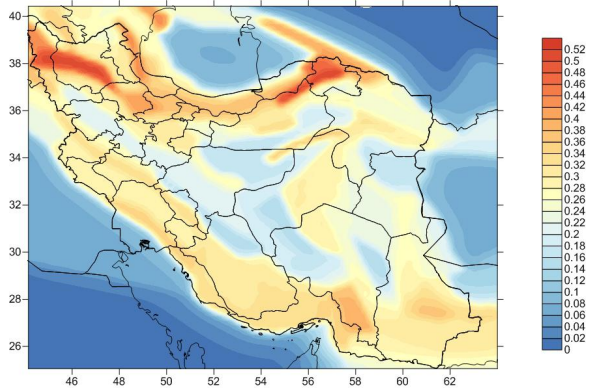

(b)

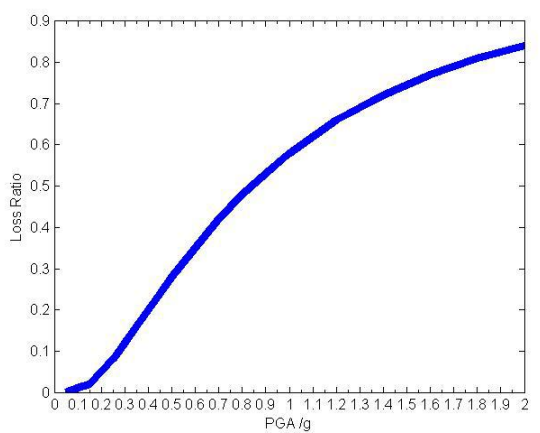

(c)

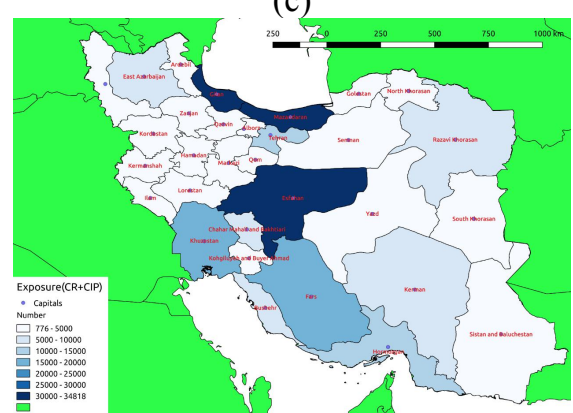

(d)

Figure 2. (a) Provinces of Iran; (b) Seismic hazard of Iran; (c) Vulnerability curve of reinforced concrete building; (d) Exposure model of reinforced concrete building 
We calculate the provincial seismic risk of Iran (loss with $10 \%$ probability of exceedance in 50 years, in US dollar) with OpenQuake. The result map is shown in Figure 3. It can be indicated that the southeastern part of Iran has higher seismic risk.

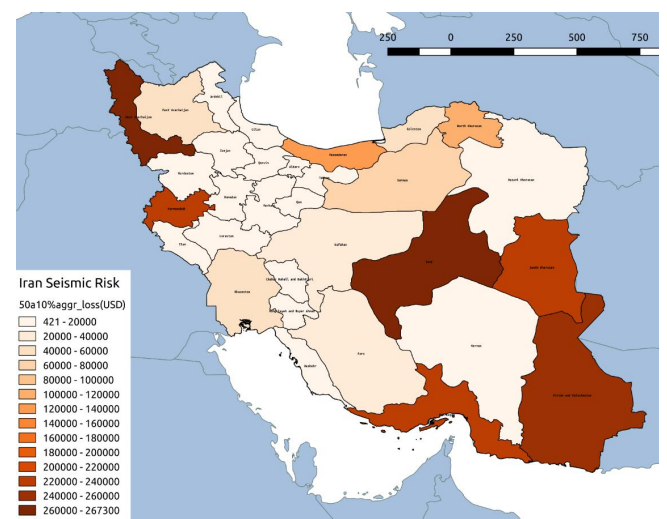

Figure 3. Map of loss with $10 \%$ probability of exceedance in 50 years of Iran

\section{Conclusion}

It can be concluded that:

(1)GEM provides the theoretical support and powerful tools to help the government in seismic risk assessment and disaster scenarios establishment. Using various earthquake risk models in OpenQuake, it is possible to set various parameters of an earthquake disaster finely, and to construct a precise, reliable, concrete and intuitive earthquake disaster scenario, and to provide information for planning and disaster preparedness of the government.

(2)The southeastern part of Iran has higher seismic risk where may suffer serious loss from earthquake disasters in the next 50 years.

\section{Reference}

[1] Crowley H, Colombi M, Crempien J, et al. 2010. GEM1 Seismic Risk Report: Part 1, GEM Technical Report 2010-5 [R]. GEM Foundation, Pavia, Italy.
[2] Danciu L, Giardini D, Sesetyan K. 2015. Seismic Hazard Assessment in the Middle East Region [R]. Earthquake Model of the Middle East Region Project.

[3] Danciu L, Monelli D, Pagani M, et al. 2010. GEM1 Hazard: Review of PSHA software, GEM Technical Report 2010-2 [R], GEM Foundation, Pavia, Italy.

[4] Pagani M, Garcia J, Monelli D, et al. 2015. A summary of hazard datasets and guidelines supported by the Global Earthquake Model during the first implementation phase. Annals of Geophysics [J], 58 (1) : S0108.

[5] Silva V, Crowley H, Pagani M, et al. 2012. Development and application of OpenQuake, an open source software for seismic risk assessment [C]. Proceedings of the 15th World Conference on Earthquake Engineering, Lisbon, Paper No. 4923.

[6] Stewart J P, Douglas J, Di Alessandro C, et al. 2012a. Selection of a global set of GMPEs for the GEM-PEER Global GMPEs Project $[C]$. Proceedings of the 15th World Conference on Earthquake Engineering, Lisbon, Paper No. 2320.

[7] Weatherill G A, Pagani M, Monelli D. 2012. The Hazard Component of the GEM Modeller' s Toolkit: A Framework for the Preparation and Analysis of Probabilistic Seismic Hazard (PSHA) Input Tools [C]. Selection of a global set of GMPEs for the GEM-PEER Global GMPEs Project. Proceedings of the 15th World Conference on Earthquake Engineering, Lisbon, Paper No. 231. 